\title{
Identifying the spatial scale of land use that most strongly influences overall river ecosystem health score
}

\author{
Fran Sheldon,,${ }^{1,5}$ Erin E. Peterson, ${ }^{2}$ Ed L. Boone, ${ }^{3}$ Suzanne Sippel,${ }^{4}$ Stuart E. Bunn, ${ }^{1}$ and Bronwyn D. Harch ${ }^{2}$ \\ ${ }^{1}$ Australian Rivers Institute, Griffith University, Nathan, Queensland 4111 Australia \\ ${ }^{2}$ CSIRO Division of Mathematics, Informatics and Statistics, Dutton Park, Queensland 4102 Australia \\ ${ }^{3}$ Statistical Sciences and Operations Research, Virginia Commonwealth University, Richmond, Virginia 23284 USA \\ ${ }^{4}$ DOE Great Lakes Bioenergy Research Center, Kellogg Biological Station, Hickory Corners, Michigan 49060 USA
}

\begin{abstract}
Catchment and riparian degradation has resulted in declining ecosystem health of streams worldwide. With restoration a priority in many regions, there is an increasing interest in the scale at which land use influences stream ecosystem health. Our goal was to use a substantial data set collected as part of a monitoring program (the Southeast Queensland, Australia, Ecological Health Monitoring Program data set, collected at 116 sites over six years) to identify the spatial scale of land use, or the combination of spatial scales, that most strongly influences overall ecosystem health. In addition, we aimed to determine whether the most influential scale differed for different aspects of ecosystem health. We used linear-mixed models and a Bayesian model-averaging approach to generate models for the overall aggregated ecosystem health score and for each of the five component indicators (fish, macroinvertebrates, water quality, nutrients, and ecosystem processes) that make up the score.

Dense forest close to the survey site, mid-dense forest in the hydrologically active nearstream areas of the catchment, urbanization in the riparian buffer, and tree cover at the reach scale were all significant in explaining ecosystem health, suggesting an overriding influence of forest cover, particularly close to the stream. Season and antecedent rainfall were also important explanatory variables, with some land-use variables showing significant seasonal interactions. There were also differential influences of land use for each of the component indicators. Our approach is useful given that restoring general ecosystem health is the focus of many stream restoration projects; it allowed us to predict the scale and catchment position of restoration that would result in the greatest improvement of ecosystem health in the regions streams and rivers. The models we generated suggested that good ecosystem health can be maintained in catchments where $80 \%$ of hydrologically active areas in close proximity to the stream have mid-dense forest cover and moderate health can be obtained with $60 \%$ cover.
\end{abstract}

Key words: ecosystem health; freshwater; indicators; land use; restoration; spatial scale.

\section{INTRODUCTION}

It has long been recognized that stream ecosystems are strongly influenced by the landscapes through which they flow (Hynes 1975, Allan 2004). The climate, topography, geology, and vegetation of a catchment drive the geomorphic processes that shape the channel network and supply water, sediment, and woody debris (Frissell et al. 1986). These catchment features influence water chemistry and ecosystem processes in streams and rivers, including the supply of nutrients and carbon and, in part, the light regime that controls the production of aquatic plants: "in every respect, the valley rules the stream" (Hynes 1975). With such strong linkages between catchments and their streams it is not surprising that changes in catchment land use can have significant impacts on stream-ecosystem health (Allan 2004).

Manuscript received 4 October 2012; revised 1 May 2012; accepted 3 May 2012. Corresponding Editor: C. Nilsson.

${ }^{5}$ E-mail: f.sheldon@griffith.edu.au
With increasing catchment and riparian degradation there has been an increasing interest in the scale at which land use within stream catchments influences aspects of stream ecosystem health (Allan 2004). Catchment-scale forest cover has been shown to influence fish, macroinvertebrate and algal biomass (Stephenson and Morin 2009), biotic diversity (Sandin and Johnson 2004, Weijters et al. 2009), instream water quality (Johnson et al. 1997, Tong and Chen 2002), benthic primary production (Fellows et al. 2006), and instream nutrients (Udy et al. 2006). In at least one study, catchment-scale forest cover was more strongly correlated with ecological response than the riparian or buffer scale (Stephenson and Morin 2009). Although the general pattern of reduced forest cover associated with decreased biodiversity holds in most instances, the species level response can be complex, with cleared landscapes and the resulting increased light availability, and often increased nutrient runoff, found to favor some species over others (Sonoda et al. 2001). 
Removal of forest cover in catchments and riparian zones is only one of many land-use impacts on streams (Vörösmarty et al. 2010). Urbanization and land-use change, from grazing or pasture land to intensive cropping and irrigated agriculture, also have negative outcomes for stream ecosystem health (Walsh et al. 2007), where ecosystem health is defined in terms of ecological integrity: the capacity of the river or stream to maintain ecosystem structure and function (Karr 1999). In urban areas, the increase in the catchment area covered by impervious surfaces, and the resulting changes in hydrology have been attributed to observed declines in stream macroinvertebrate diversity (Walsh et al. 2007) and loss of specific taxa (Utz et al. 2009).

Most studies of land-use impacts on stream ecosystem health have focused on specific indices of ecosystem health, such as macroinvertebrate diversity (Stephenson and Morin 2009), fish abundance (Kennard et al. 2006), water quality (Tong and Chen 2002), stream ecosystem processes (Fellows et al. 2006), and nutrients (Udy et al. 2006). These indices are likely to respond to land-use change or disturbance gradients at different spatial scales given the diverse processes driving them (Bunn et al. 2010). In some cases, a single score is used to assess stream health, which focuses on one ecosystem function, or group. Examples of this approach include the AusRivAS score using macroinvertebrates in Australia (Smith et al. 1999) and RIVPACS in the UK (Wright et al. 1993), or the index of biotic integrity, often used for assessing health using fish (Harris and Silveira 1999). While these approaches assess health using one taxonomic group, it is becoming more common to use a suite of normalized ecosystem health indices derived from multiple taxonomic groups and ecosystem processes, which are then aggregated to provide an overall assessment of ecosystem health as a single "score" (Williams et al. 2009, Bunn et al. 2010). In Victoria, Australia, stream health is reported by the Index of Stream Condition (ISC) (Ladson et al. 1999), which incorporates measures of hydrology, physical channel form, characteristics of the riparian or floodplain vegetation, water quality, and macroinvertebrates. Although individual indices have been shown to respond to land-use change, it is unclear whether aggregated scores representing ecosystem health are similarly responsive. Yet, catchment and riparian restoration activities are often spatially targeted to improve general stream health, as quantified by an aggregated score, rather than focusing on specific taxa or taxa groups.

In South-east Queensland (SEQ), Australia, the Ecological Health Monitoring Program (EHMP) reports on the ecological health of the region's streams and rivers once a year via a report card grading process that reflects a single EHMP score generated from 14 separate indices (Bunn et al. 2010, Healthy Waterways Partnership 2012). These individual indices were originally selected because they were correlated with a gradient of stream disturbance, which included catch- ment, riparian, and reach-scale land-use change, channel condition, and site-scale water quality (Bunn et al. [2010] for a complete description). For example, the thermal regime of small SEQ streams responds to changes in local shading at the scale of hundreds of meters of channel (Rutherford et al. 2004), while benthic-algal biomass is largely explained by riparian canopy cover at the local scale $(<100 \mathrm{~m}$ reach; Mosisch et al. 2001). In contrast, other ecosystem-health indicators appear to be more strongly influenced by broader-scale land use or land use at a combination of scales. A significant percentage of the observed variation in benthic production is explained by the proportion of pasture land in the upstream catchment (Bunn et al. 1999) as well as local riparian condition (Fellows et al. 2006). The abundance and biomass of alien fish recorded in SEQ streams were also explained by a combination of riparian, reach-scale, and catchment-scale influences (Kennard et al. 2005). In addition, the spatial location of land-use patches in the upstream catchment with respect to the assessment site or the stream also appears to influence indices of ecosystem health (Peterson et al. 2011).

In this paper, we use a data set collected over six years to explore the influence of land use at three spatial scales on stream ecosystem health. Our goal was to identify the scale of land use that most strongly influenced the overall aggregated ecosystem health score and to determine whether the most influential scale differed for the five ecosystem-health indicators that make up the score. We then used this knowledge to recommend the scale of catchment restoration that would be required to improve the ecosystem health of the regions streams and rivers.

\section{Methods \\ Study area}

The SEQ region in Australia (22 $\left.353 \mathrm{~km}^{2}\right)$ stretches from the Noosa River in the north to the Gold Coast catchments in the south and west to the top of the Brisbane River catchment just east of the city of Toowoomba; it covers six major river catchments and includes the 15 major rivers of the Moreton Bay region (Fig. 1; Abal et al. 2005). The SEQ region is subtropical with a median annual rainfall of $1500 \mathrm{~mm}$ (Abal et al. 2005); the majority of this occurs during the hot wet summers, which are contrasted by cool dry winters. SEQ also has one of the fastest growing populations in Australia, with just over 2 million people, increasing by $2.9 \%$ per annum (Abal et al. 2005). Less than $60 \%$ of the endemic vegetation remains in many subcatchments and riparian zones have been heavily disturbed (Bunn et al. 1999). However, there are also extensive areas of conservation, with managed and plantation forests throughout the region, particularly along the southern and western regional boundary, the Lamington Plateau and the Western Boundary Ranges (Abal et al. 2005). Headwater streams are typically characterized by 


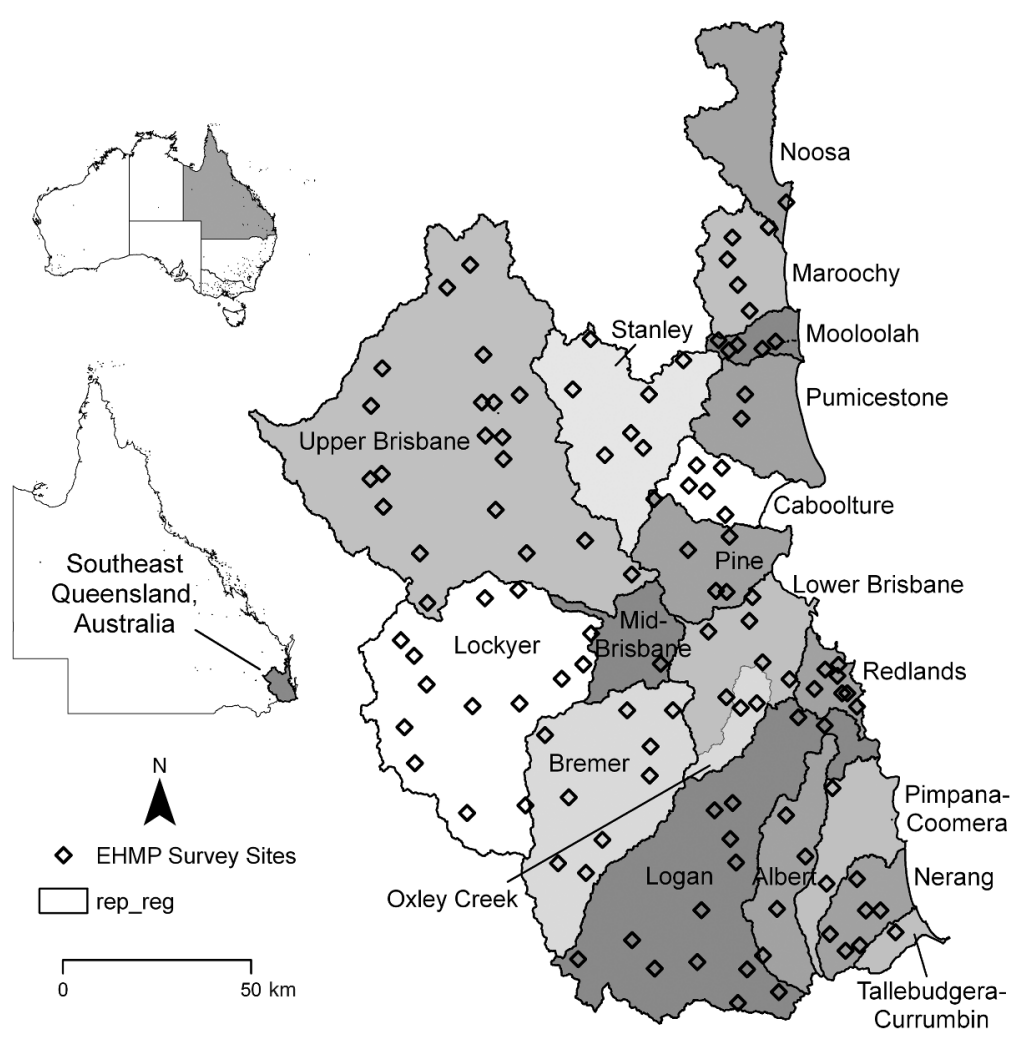

FIG. 1. Ecological Health Monitoring Program (EHMP) survey sites are collected throughout 19 EHMP reporting regions in Southeast Queensland, Australia.

forested land use, while lowland streams and rivers are dominated by agricultural and urban land use.

\section{The Freshwater Ecological Health Monitoring Program (EHMP)}

The Freshwater EHMP was implemented in 2002 and now forms the basis for the annual regional Report Card for the region's waterways (Bunn et al. 2010). Freshwater ecosystem-health data are collected biannually at 127 sites (as of 2008), during the austral spring (pre-wet) and austral autumn (post-wet). These sites are representative of headwaters and middle sized streams (second- and third-order streams) in the region and are distributed throughout major land-use types to enable reporting of stream ecosystem health at a regional scale. Data are collected for five groups of indicators: water quality, fish, macroinvertebrate, ecosystem processes, and nutrient indicators, with each indicator type comprised of multiple indices (Fig. 2; Bunn et al. 2010). The annual EHMP site score represents an aggregation of 14 ecosystem health indices, collected over two seasons (Fig. 2). Data for each index are converted to a standardized score by comparing the observed value at a site with a reference condition (Bunn et al. 2010). Standardized scores range from 0 (maximum deviation from reference condition) to 1 (equal to reference condition). Standardized scores for the indices, within indicator type, are averaged to create a score between 0 and 1 for each indicator at a site. The scores for all five indicators are then averaged to create a seasonal score between 0 and 1 for a site. The two seasonal site scores for each year starting in the austral spring (e.g., spring 2003 and autumn 2004) are averaged to give an annual site score. These annual site scores are then averaged across each catchment and converted into a report card grade (Fig. 2), which is released as part of an annual report card for ecosystem health in SEQ streams (Bunn et al. 2010, Healthy Waterways Partnership 2012). Note that, when data are missing, the scores are calculated in the same way using the remaining data; this however was not a systematic problem for any one indicator apart from the nutrient indicator, which requires the collection on an algal sample for the determination of $\delta^{15} \mathrm{~N}$, and this can be difficult after periods of high flow. For this analysis, site scores for each season (pre-wet and post-wet) were used from 116 EHMP sites sampled between the years 2002 and 2008.

\section{GIS methods}

Land use and land-cover (LULC) characteristics were calculated for 116 EHMP sites at catchment, riparian, and reach scales (Fig. 3). The catchment scale represents the entire drainage area upstream from each EHMP survey site (Fig. 3a), while the riparian scale represents the land within the catchment located within $25 \mathrm{~m}$ of the stream (Fig. 3b). The reach scale is a subset of the 
TABLE 1. Land-use and land-cover categories used to calculate explanatory variables at the catchment, riparian, and reach scale.

\begin{tabular}{llll}
\hline \hline Land-use code & \multicolumn{1}{c}{ Scale } & \multicolumn{1}{c}{ Description } & Source \\
\hline Urban & catchment and riparian & urbanized land use & QLUMP (BRS 1999) \\
Cleared & catchment & cleared land use & QLUMP (BRS 1999) \\
Crop & catchment and riparian & crop land use & QLUMP (BRS 1999) \\
Pasture & catchment and riparian & pasture land use & QLUMP (BRS 1999) \\
VSF & catchment and riparian & very sparse woody vegetation & Kuhnell et al. (1998) \\
SF & catchment and riparian & sparse woody vegetation & Kuhnell et al. (1998) \\
MDF & catchment and riparian & mid-dense woody vegetation & Kuhnell et al. (1998) \\
DF & catchment and riparian & dense woody vegetation & Kuhnell et al. (1998) \\
Crop & reach & crop land use & DERM (2008) \\
Grass & reach & grasslands & DERM (2008) \\
Urban & reach & residential or urban land use & DERM (2008) \\
Trees & reach & tree cover & DERM (2008) \\
\hline
\end{tabular}

Notes: All catchment-scale metrics included lumped, inverse flow length to the outlet (iFLO), inverse flow length to the stream (iFLS), and hydrologically active inverse flow length to the outlet (HA-iFLO) and to the stream (HA-iFLS). Riparian and reachscale attributed metrics were calculated using the lumped metrics.

riparian scale and only includes the riparian area in the $25 \mathrm{~m}$ buffer from the EHMP site $(0 \mathrm{~m})$ extending upstream for $1000 \mathrm{~m}$ (Fig. 3c). The stream data were supplied by the Moreton Bay Waterways and Catchments Partnership (2005) (see Peterson et al. [2011] for details about the stream and EHMP site data sets, as well as the GIS preprocessing).

We used the Queensland Land-Use Mapping Program (QLUMP) data set (BRS 2002) and the Statewide Landcover and Trees Study (SLATS) derived 2001 Foliage Projective Cover (FPC) data set (Kuhnell et al. 1998) to generate 10 land-use and land-cover
(LULC) rasters (Table 1), with a 25-m spatial resolution. The land-use rasters were derived from the QLUMP data set and included urban (urban), cropping (crop), and pasture (pasture) land uses. The SLATS FPC data were categorized based on the specifications of Specht et al. (1974) and used to derive rasters for four land-cover categories: very sparse forest (VSF), sparse forest (SF), mid-dense forest (MDF), and dense forest (DF). Details concerning the GIS pre-processing of the LULC data sets are also provided in Peterson et al. (2011). Composition metrics based on lumped attributes (e.g., areal percentages of land use within an area), were

\section{Sampled seasonally each spring and autumn}

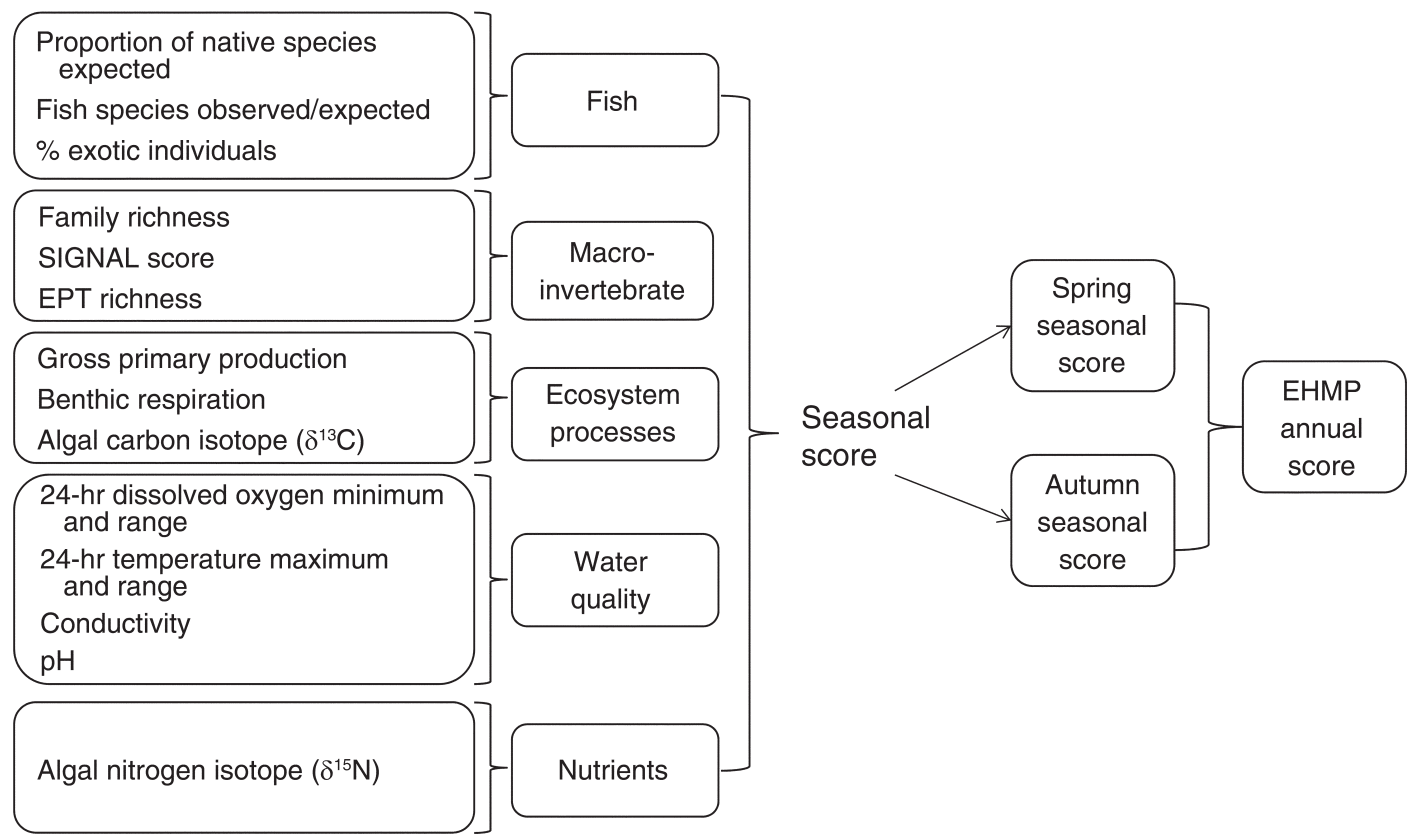

FIG. 2. Diagram of the calculation of the annual EHMP score calculated for each site. The average annual site score for each reporting catchment $(0-1)$ is then converted to a report card grade by averaging all site scores in each report card catchment with grades boundaries as A (1.000-0.925), B (0.924-0.850), C (0.849-0.775), D (0.774-0.700), and F (<0.700); a grade of A suggests excellent health while a grade of $\mathrm{F}$ is considered a fail. EPT stands for Ephemeroptera, Plecoptera, and Trichoptera. SIGNAL scores are an index in the EHMP. 
calculated using the seven LULC data sets at the catchment and riparian scales (Table 1).

Lumped attributes are commonly used to characterize catchment land use in aquatic studies (Johnson et al. 1997, Peterson et al. 2006), but they are nonspatial and do not account for either the disproportionate influence of land located near the stream or land with high rates of overland flow. Recent research suggests that spatially explicit landscape-representation methods have the ability to explain additional variability in instream indicators of ecosystem health in SEQ (Peterson et al. 2011). Therefore, two inverse-distance-weighted (IDW) catchment attributes, which account for the proximity of land to the stream or stream outlet (i.e., the EHMP survey site), were also calculated for each of the LULC categories (Table 1): inverse-flow length to the stream (iFLS) and inverse-flow length to the outlet (iFLO). An IDW metric uses a distance-decay function to give a stronger weight to land use closer to a specific feature of interest. The general formula shown in Eq. 1 is used to calculate the IDW metric (percentage) for each land-use type separately:

$$
\mathrm{LU}=\frac{\sum_{i=1}^{n} I(k) W_{i}}{\sum_{i=1}^{n} W_{i}} \times 100 .
$$

In this case $W_{i}$ is the inverse-distance weighting, $(d+$ $1)^{-1}$, from every cell in the catchment to either the survey site or the stream, with $0<W_{i} \leq 1$. Distance, $d$, is represented using the flow length to either the outlet or the stream, with the units determined by the projection of the data set. $I(k)$ is an indicator function, indicating whether each cell represents the land use of interest, $k=$ 1 , or another land-use type, $k=0$. Note that Eq. 1 could also be used to calculate the lumped metric if a uniform weighting, $W_{i}=1$, was used.

Land use found in preferential overland-flow pathways may also influence the conditions found at the survey site (Stauffer et al. 2000, Peterson et al. 2011). Thus, two additional IDW attributes were calculated for each of the catchment-scale LULC categories that account for proximity to the stream or outlet and the potential for hydrologic activity: hydrologically active inverse-flow length to the outlet (HA-iFLO) and to the stream (HA-iFLS). The general form of the hydrologically active inverse-distance weighted (HA-IDW) metric (percentage) is

$$
\mathrm{LU}=\frac{\sum_{i=1}^{n} I(k) W_{i} \mathrm{FA}_{i}}{\sum_{i=1}^{n} W_{i} \mathrm{FA}_{i}} \times 100 .
$$

$\mathrm{FA}_{i}$ is the flow accumulation value for each cell, where $\mathrm{FA}_{i} \geq 0$. Assuming that all precipitation results in overland flow, FA represents the number of upslope cells that contribute flow into each downslope cell based on the topography of the catchment. Additional information about the derivation of the catchment-scale attributes can be found in Peterson et al. (2011).

Land use and land cover at the reach scale were characterized using orthorectified aerial photographs with a $0.6 \mathrm{~m}$ spatial resolution, taken between 2001 and 2007 (DERM 2008). Land-use types, including crop, residential/urban (urban), grass (grass), and trees (trees), were visually identified and manually digitized. Lumped metrics were also calculated for each of the four LULC types at the reach scale. In total, 46 LULC explanatory variables were calculated (Table 1). These included 35 catchment-scale variables $(5$ metric types $\times 7$ LULC categories), seven riparian-scale LULC categories, and four reach-scale LULC variables).

\section{Rainfall}

The seasonal expansion and contraction of the stream network (Malard et al. 1999) may affect the relative influence of catchment land use on in-stream indicators (Johnson et al. 1997, Young and Collier 2009). In the wet season, the stream network expands both longitudinally and laterally, which results in a flushing effect as the flow paths facilitate the movement of physical material, chemicals, and nutrients to and within the stream (Robertson et al. 1999). During dry periods, there is less precipitation and the stream network contracts, resulting in reduced connectivity and movement of material (Malard et al. 1999). Thus, we expected scores to be more strongly related to land use at the catchment and riparian scales during the post-wet season compared to the pre-wet season. However, SEQ experienced drier and more variable rainfall patterns from 2002 to 2008, which could mask this seasonal variability. Therefore, variables describing variation in rainfall across sites during the sampling period were also calculated.

Interpolated mean daily rainfall $(\mathrm{mm} / \mathrm{d})$ data were obtained from the Australian Bureau of Meteorology (Jeffrey et al. 2001) and used to calculate the deviation from standard rainfall for each EHMP site. The data had a relatively coarse spatial resolution $\left(5 \mathrm{~km}^{2}\right)$, but were available daily from January 2001 to March 2008. The short-term mean total rainfall in the catchment for the 90 days prior to sampling was calculated for each site visit. The mean total rainfall between 2001 and 2008 (i.e., long-term mean) was also calculated for the 90 days prior to the day and month of sampling for each site visit. Then, the deviation of short-term mean rainfall from the long-term total mean rainfall was calculated (hereafter referred to as the rainfall deviation).

\section{Statistical methods}

We collated EHMP scores from 116 sites across 12 sampling occasions (six years) to produce our data set, which contained a total of 1273 measurements (i.e., EHMP scores). Some sites could not be sampled every 
a) Lumped
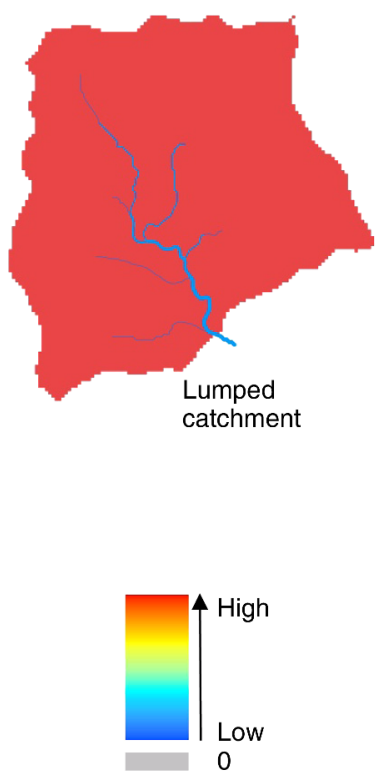

b) IDW
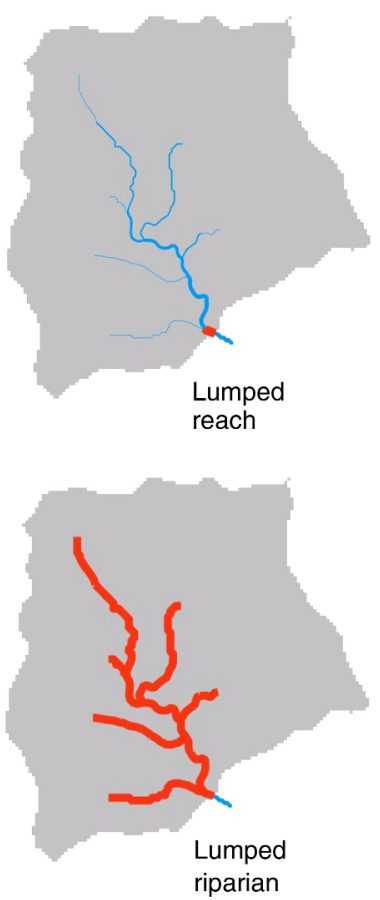

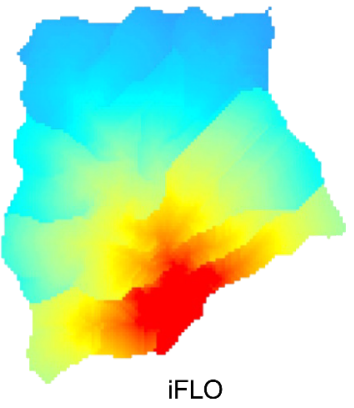

iFLO

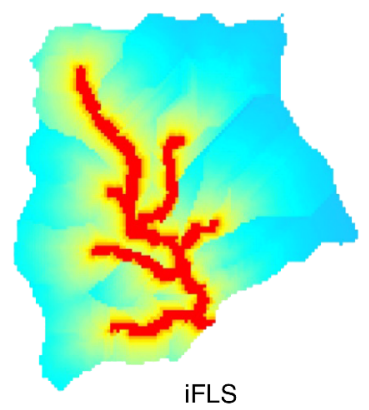

c) HA-IDW

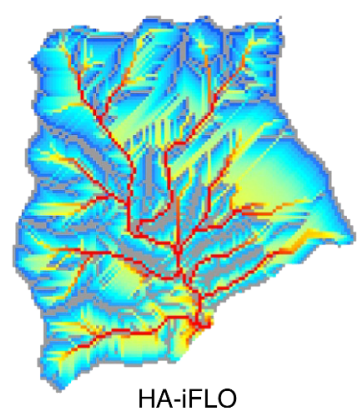

HA-iFLO

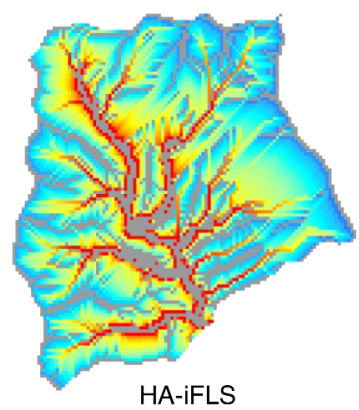

FIG. 3. Graphical representation of the spatial scales of influence. (a) The lumped attributes are nonspatial and include "lumped catchment" representing the entire drainage area upstream from each EHMP survey site, "lumped riparian" representing those catchment areas that are within $25 \mathrm{~m}$ of the stream, and "lumped reach" restricted to those areas within $25 \mathrm{~m}$ of the stream, which are within $1 \mathrm{~km}$ upstream from the EHMP survey site. (b) The inverse-distance-weighted (IDW) catchment attributes account for the proximity of land-use and include inverse-flow length to the stream (iFLS) and inverse-flow length to the outlet or site (iFLO). (c) The hydrologically active inverse-distance-weighted (HA-IDW) catchment attributes account for both the proximity of land use and the potential for hydrologic activity; they include hydrologically active inverse-flow length to the stream (HA-iFLS) and to the outlet, or site (HA-iFLO). The figure is modified from Peterson et al. (2011).

year due to lack of flowing water and so the number of measurements at each site ranged between 4 and 12 . We transformed the seasonal scores using the logit transformation, which ensured that model predictions were restricted to the 0 to 1 range and allowed for additional differentiation between groups when the values were close to the bounds (Piepho 2003). The logit transformation is given by

$$
\operatorname{logit}(y)=\ln \left(\frac{y}{1-y}\right) .
$$

A linear-mixed modeling approach was used to account for spatial and temporal variation in the transformed scores. Linear-mixed models may include both random and fixed effects, which is particularly useful for modeling spatially distributed data, with repeated measurements. A random intercept at each site was also included in all models to account for site-specific spatial variability that was not accounted for. The general form of a linear-mixed model is given by

$$
y=\mathbf{X} \beta+\mathbf{Z} \gamma+\varepsilon
$$

where $\mathbf{X}$ is a matrix of explanatory variables for each site and time and $\mathbf{Z}$ is a matrix of explanatory variables for each site, regardless of time (Pinheiro and Bates 2008).

We used a large number of LULC variables, derived at the three nested spatial scales (catchment, riparian, and reach), which we expected to be collinear. As such, it would be inappropriate to consider the full suite of potential explanatory variables using common modelselection strategies, such as forward, backward or stepwise selection (Mills and Prasad 1992, Kutner et al. 2004). The use of principal-components analysis is a common technique for dealing with highly correlated explanatory variables, but it was not applicable here because we were specifically interested in the influence of a spatial scale, rather than a linear combination of spatial scales. Therefore, we used a Bayesian modelaveraging approach to assess the impact of land use at different spatial scales.

First, we constructed a list of candidate models, with the requirement that for each land-use type, only one scale and its seasonal interaction were permitted in the model (Table 1). For example, a model containing MDF iFLO and DF iFLO would be permitted because MDF and DF are different land-use types; however, a model containing iFLO and riparian-scale MDF or iFLO and 
MDF HA-iFLO would not be permitted since MDF would be represented using two different scales or metric types. Temporal explanatory variables characterizing season $(1=$ post-wet and $0=$ pre-wet $)$ and rainfall deviation were also included in all models.

Every linear combination of potential explanatory variables produced 629407744 candidate models and so an exhaustive model search was impossible. In addition, we expected LULC explanatory variables calculated at nested spatial scales or using different metrics to be correlated. Therefore, we employed a stochastic-model search to efficiently identify the most influential explanatory variables, as well as ensure that collinear LULC explanatory variables were not included within the same model. The stochastic model search consisted of 10 chains of 10000 steps to produce a total of 100000 models and was conducted as described in Appendix A.

The posterior probability $\left(P\left(M_{i} \mid D\right)\right.$ for each of the models given the data set $D$ (Hoeting et al. 1999) was then calculated using the 100000 models:

$$
P\left(M_{i} \mid D\right)=\frac{P\left(D \mid M_{i}\right) P\left(M_{i}\right)}{\sum_{j=1}^{m} P\left(D \mid M_{j}\right) P\left(M_{j}\right)} \approx \frac{\exp \left(-\frac{1}{2} \mathrm{BIC}_{i}\right)}{\sum_{j=1}^{m} \exp \left(-\frac{1}{2} \mathrm{BIC}_{j}\right)},
$$

where $M_{i}$ is the model of interest, $M_{j}\left(M_{j}=1, \ldots, m\right)$ are the 99999 alternative models, and $\mathrm{BIC}_{i}$ and $\mathrm{BIC}_{j}$ are the Bayesian information criterion (BIC) values for models $M_{i}$ and $M_{j}$, respectively. The posterior model probabilities were then used to derive the model-averaged distribution for the coefficients, $\beta$ :

$$
p(\beta \mid D)=\sum_{j=1}^{m} p\left(\beta \mid M_{j}, D\right) P\left(M_{j} \mid D\right) .
$$

Models with a posterior probability of 0.0001 or higher were used to calculate the model-averaged means, standard errors, and inclusion probabilities.

The statistical methods described in Appendix A were also applied to a subset of the annual scores data set, with linear-mixed models fit to each of the five seasonal-indicator scores: fish, macroinvertebrates, ecosystem processes, nutrients, and water quality. There were no missing values in the subset of indicator data, which included 349 pre-wet and 336 post-wet season observations, collected at 110 EHMP sites. A logit transformation was applied to each of the indicator scores prior to analysis. All of the statistical analyses for the scores and indicators were undertaken in $\mathrm{R}$ statistical software (R Development Core Team 2006) using the lme4 package or custom $\mathrm{R}$ scripts (package available online). ${ }^{6}$

${ }^{6}$ http://cran.r-project.org/web/packages/lme4/index.html

\section{Restoration scenarios}

We selected three catchments with different background river ecosystem health to assess the influence that increasing tree cover in the upstream catchment would have on the seasonal report card grade. The catchment with good ecosystem health was the Mooloolah River Catchment in the north of the SEQ Region, covering an area of $223 \mathrm{~km}^{2}$ with a stream network length of $322 \mathrm{~km}$. There are five EHMP sites within the Mooloolah catchment with report card grades ranging from a C in 2003, a B in 2004-2008 and an A- in 2004. The catchment with fair ecosystem health was the Caboolture River Catchment, north of Brisbane, covering an area of $468 \mathrm{~km}^{2}$ with a stream-network length of $795 \mathrm{~km}$. Five sites are sampled in the Caboolture catchment with report card grades ranging from $\mathrm{C}+$ in 2007 and 2008 to $\mathrm{B}+$ in 2003. In comparison, a catchment that has remained in comparatively poor health from 2002 to 2008 is the highly urbanized Redlands catchment in the Moreton Bay region. The Redlands catchment has a total area of $281 \mathrm{~km}^{2}$ with a stream-network length of $525 \mathrm{~km}$. Seven sites have been sampled in the Redlands catchment and streams have remained in very poor condition throughout the sampling period, with the highest grade of C- in 2003 and a consistent grade of F since 2005 .

We used the MDF HA-iFLS metric to explore the influence of restoration on the EHMP score as it had the highest inclusion probability of all the land-use types, scales, and metrics. A subset of data was created for each of the 17 sites in the Mooloolah, Calboolture, and Redlands catchments. The 17 data sets included the last seasonal score, as well as the explanatory variables associated with that score, with the exception of MDF HA-iFLS. Each of the 17 data sets was expanded to create 101 new data sets with MDF HA-iFLS values ranging between 0 and 100 . Hereafter, we will refer to these 101 data sets as the scenarios data set for each site. All models with a posterior-inclusion probability greater than 0.0001 were used to predict the seasonal score, $\hat{y}_{\text {new }}$. Then, the model-averaged seasonal score at a site was calculated:

$$
E\left[\hat{y}_{\text {new }} \mid D\right]=\sum_{i=1}^{m} E\left(\hat{y}_{\text {new }} \mid M_{i}, D\right) P\left(M_{i} \mid D\right)
$$

where $E\left[\hat{y}_{\text {new }} \mid D\right]$ is the expected value of $\hat{y}_{\text {new }}$. The predicted scores for each site within a catchment were also averaged to produce a catchment-wide seasonal score.

\section{Results}

\section{EHMP score}

There was some seasonal variation in EHMP score, with scores tending to be lower in the pre-wet (range $0.46-0.99$ ) compared with the post-wet season (range 0.50-0.99; Table 2). The median annual EHMP score (for years 2002-2008) for sites obtaining a grade of A 
TABle 2. Ecosystem Health Monitoring Program (EHMP) scores and individual component indicator scores, by season, for years 2002-2008.

\begin{tabular}{|c|c|c|c|c|c|c|}
\hline \multirow[b]{2}{*}{ Year } & \multirow[b]{2}{*}{ Score } & \multicolumn{5}{|c|}{ Component indicator scores } \\
\hline & & $\begin{array}{l}\text { Water } \\
\text { quality }\end{array}$ & Macroinvertebrates & Fish & Metabolism & Nutrients \\
\hline \multicolumn{7}{|c|}{ Pre-west season } \\
\hline 2002 & $0.76(0.13)$ & $0.77(0.18)$ & $0.81(0.13)$ & $0.56(0.24)$ & $0.77(0.21)$ & $0.80(0.36)$ \\
\hline 2003 & $0.77(0.11)$ & $0.75(0.19)$ & $0.73(0.24)$ & $0.72(0.23)$ & $0.75(0.20)$ & $0.86(0.27)$ \\
\hline 2004 & $0.78(0.13)$ & $0.79(0.17)$ & $0.85(0.15)$ & $0.76(0.21)$ & $0.79(0.19)$ & $0.68(0.38)$ \\
\hline 2005 & $0.75(0.13)$ & $0.85(0.12)$ & $0.82(0.19)$ & $0.74(0.18)$ & $0.84(0.16)$ & $0.66(0.39)$ \\
\hline 2006 & $0.77(0.14)$ & $0.81(0.17)$ & $0.75(0.22)$ & $0.69(0.21)$ & $0.87(0.13)$ & $0.78(0.35)$ \\
\hline 2007 & $0.73(0.15)$ & $0.84(0.14)$ & $0.71(0.20)$ & $0.66(0.24)$ & $0.82(0.17)$ & $0.72(0.36)$ \\
\hline \multicolumn{7}{|c|}{ Post-wet season } \\
\hline 2003 & $0.80(0.14)$ & $0.90(0.14)$ & $0.78(0.19)$ & $0.63(0.23)$ & $0.85(0.17)$ & $0.79(0.32)$ \\
\hline 2004 & $0.83(0.13)$ & $0.91(0.12)$ & $0.84(0.16)$ & $0.74(0.20)$ & $0.84(0.15)$ & $0.76(0.35)$ \\
\hline 2005 & $0.79(0.14)$ & $0.87(0.17)$ & $0.81(0.18)$ & $0.70(0.22)$ & $0.85(0.17)$ & $0.78(0.36)$ \\
\hline 2006 & $0.80(0.13)$ & $0.91(0.11)$ & $0.80(0.19)$ & $0.76(0.21)$ & $0.87(0.13)$ & $0.79(0.32)$ \\
\hline 2007 & $0.74(0.14)$ & $0.85(0.13)$ & $0.72(0.23)$ & $0.70(0.21)$ & $0.84(0.17)$ & $0.76(0.36)$ \\
\hline 2008 & $0.80(0.12)$ & $0.92(0.10)$ & $0.82(0.17)$ & $0.68(0.23)$ & $0.84(0.16)$ & $0.70(0.36)$ \\
\hline
\end{tabular}

Notes: Values are means with SD in parentheses. The indicator scores were derived using a subset of the data used to calculate the score.

(Fig. 2; Bunn et al. 2010, Healthy Waterways Partnership 2012) was 0.955 . At these sites, the average $( \pm$ SE) DF at the catchment and riparian scales was $26 \% \pm$ $6.2 \%$, and $27 \% \pm 6.6 \%$, respectively, while the average percent tree cover at the reach scale was $86 \% \pm 5 \%$; whereas the same sites had only $5 \% \pm 2 \%$ urban land use at the catchment and riparian scales (Fig. 4). In contrast, the median annual EHMP score (years 2002 2008) for those sites obtaining a grade of $F$ was 0.655 with an average of $0.5 \% \pm 0.3 \% \mathrm{DF}$ at the catchment scale, $1 \% \pm 0.5 \% \mathrm{DF}$ at the riparian scale and $61 \% \pm$ $6 \%$ tree cover at the reach scale. In addition, all of these sites had more than $30 \% \pm 6.5 \%$ urban at both the catchment and riparian scales (Fig. 4).
Catchment

a) Dense forest and tree cover

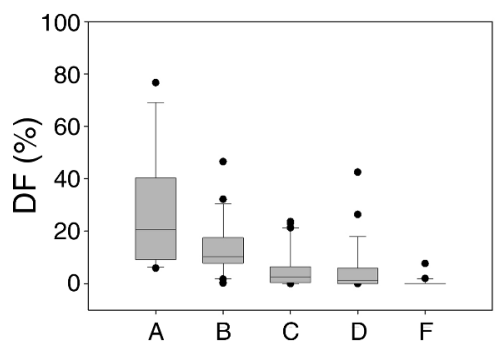

b) Urban land use

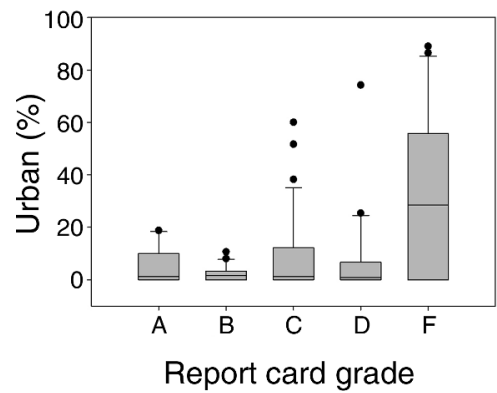

Riparian
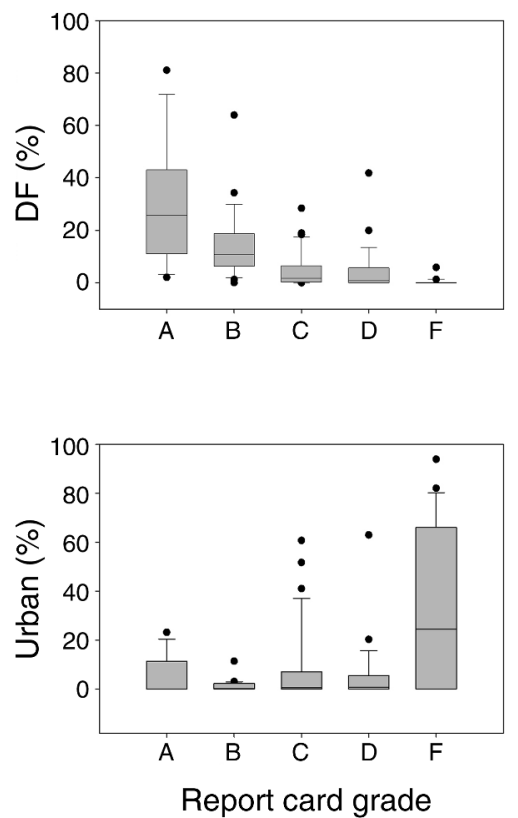

Reach
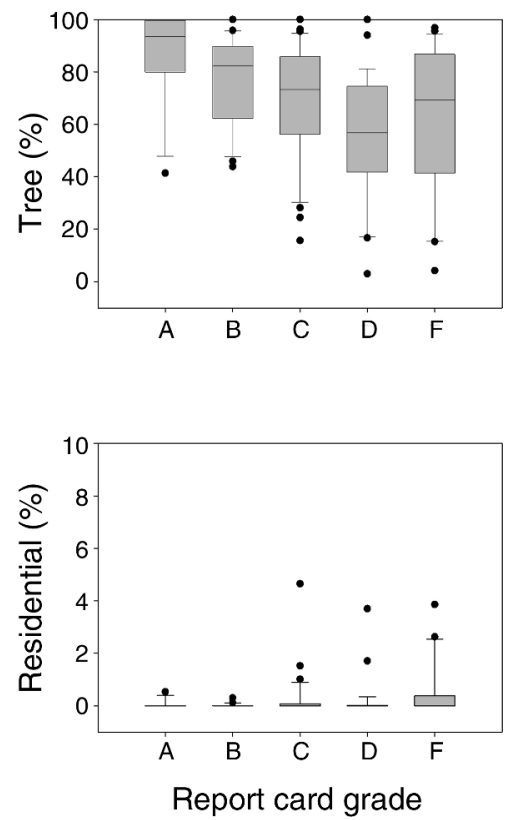

FIG. 4. Box plots showing the distribution of median annual report card grades across three lumped (or nonspatial) measures of (a) dense forest and tree cover (DF) and (b) urban land use at the catchment, riparian, and reach scale. The boundary of the box represents the 25 th and 75 th percentiles, the line within the box marks the median, error bars above and below the box indicate the 90th and 10th percentiles, and closed circles represent outlying points. 
TABLE 3. Summary of the overall EHMP score model inclusion probabilities for each land use explanatory variable calculated at the catchment, riparian, and reach scales.

\begin{tabular}{|c|c|c|c|c|c|c|c|c|c|}
\hline Scale & $\mathrm{DF}$ & MDF & $\mathrm{SF}$ & VSF & Pasture & Crop & Urban & Tree & Grass \\
\hline Main effect & 0.9990 & 0.9863 & 0.1975 & 0.1051 & 0.0844 & 0.0756 & 0.9873 & 0.1946 & 0.1946 \\
\hline Main effect $\times$ season & 0.3496 & 0.9347 & 0.0066 & 0.0212 & 0.0026 & 0.0019 & 0.0135 & 0.0021 & 0.0021 \\
\hline \multicolumn{10}{|l|}{ Catchment scale } \\
\hline Lumped & 0.3186 & 0.0007 & 0.0740 & 0.0191 & 0.0093 & 0.0110 & 0.1569 & & \\
\hline iFLO & 0.6267 & 0.0006 & 0.0173 & 0.0120 & 0.0154 & 0.0092 & 0.1099 & & \\
\hline iFLS & 0.0265 & 0.0176 & 0.0334 & 0.0174 & 0.0117 & 0.0097 & 0.2186 & & \\
\hline HA-iFLO & 0 & 0.0005 & 0.0111 & 0.0103 & 0.0228 & 0.0111 & 0.0004 & & \\
\hline HA-iFLS & 0.0027 & 0.9157 & 0.0319 & 0.0298 & 0.0135 & 0.0113 & 0.2699 & & \\
\hline Lumped $\times$ season & 0.0246 & 0 & 0.0023 & 0.0083 & 0.0005 & 0.0003 & 0.0022 & & \\
\hline iFLO $\times$ season & 0.2072 & 0 & 0.0005 & 0.0016 & 0.0004 & 0.0003 & 0.0015 & & \\
\hline iFLS $\times$ season & 0.1109 & 0.0088 & 0.0012 & 0.0059 & 0.0004 & 0.0003 & 0.0028 & & \\
\hline HA-iFLO $\times$ season & 0.0063 & 0 & 0.0004 & 0.0004 & 0.0005 & 0 & 0 & & \\
\hline HA-iFLS $\times$ season & 0 & 0.8930 & 0.0009 & 0.0008 & 0.0003 & 0.0004 & 0.0037 & & \\
\hline \multicolumn{10}{|l|}{ Riparian scale } \\
\hline Lumped & 0.0246 & 0.0512 & 0.0298 & 0.0166 & 0.0116 & 0.0100 & 0.2299 & & \\
\hline Lumped $\times$ season & 0.0006 & 0.0329 & 0.0012 & 0.0042 & 0.0004 & 0.0003 & 0.0032 & & \\
\hline \multicolumn{10}{|l|}{ Reach scale } \\
\hline Lumped & & & & & & 0.0133 & 0.0018 & 0.1946 & 0.1946 \\
\hline Lumped $\times$ season & & & & & & 0.0004 & 0.0001 & 0.0021 & 0.0021 \\
\hline
\end{tabular}

\section{Influence of land use on seasonal EHMP score}

The stochastic-model search for the EHMP score model yielded 1126 models with a posterior-model probability greater than $0.0001,135$ models with a probability larger than 0.001 , and 19 models with a probability larger than 0.01 . The top five models comprised approximately $43 \%$ of the total model probability and had similar BIC values, which suggests that all were competitive models. A visual examination of the standardized residual plots and Q-Q plots indicated that the residuals from the averaged model met the assumptions of normality and homoscedasticity. Furthermore, no residual outliers were observed or removed.

The influence of land use on the EHMP score was determined by exploring the probability of each land-use variable occurring in any model (Table 3 and Appendix B). The model coefficients indicated that rainfall deviation had a positive influence on the score (0.0625), meaning that sites that experienced aboveaverage rainfall compared to the long-term average in the 90 days prior to sampling had higher EHMP scores than those receiving less-than-average rainfall during the same period. Season had a negative influence $(-0.0413)$ with scores lower in the pre-wet compared with the postwet. Both rainfall and season had a probability of 1 (i.e., $100 \%$ ) of inclusion in any model. At the catchment scale a number of land-use variables also had a consistently high inclusion probability including DF (99\%), MDF (99\%), and urban (99\%; Table 3 and Fig. 5a). The relationship of these land-use variables to the EHMP score was as expected with both DF and MDF having a positive relationship and urban having a negative relationship (Table 4). DF close to the survey site (iFLO) had a much higher inclusion probability compared to other measures of DF (63\%) and also had the strongest positive relationship (Table 4); though lumped DF at the catchment scale also had a relatively high probability compared to other DF measures (32\%). The potential for hydrologic activity also seemed to affect the inclusion probabilities. For metrics of MDF, HA-iFLS had a positive influence on the score (Table 4) and the highest probability of being included in any model $(92 \%)$ with no other MDF metrics with an inclusion probability greater than $5 \%$ (Table 3).

Although a number of other catchment-scale land-use measures had a negative influence on the EHMP score, including urban, SF, VSF, and crop, this influence was not as strong as the positive influence of the presence of DF and MDF (Table 4). Interestingly, three urban landuse measures had a nearly equal probability of inclusion: iFLS, HA-iFLS, and riparian $(22 \%, 27 \%$, and $23 \%$, respectively). Despite their negative influence on the score, SF, VSF, crop, and pasture had a low inclusion probability compared to the other land-use variables, with none greater than $20 \%$ (Table 3).

When seasonal interactions with LULC metrics were tested only the seasonal MDF interaction had a strong probability of inclusion in any model (93\%); however, the seasonal interaction for DF also had a relatively strong inclusion probability (35\%) compared to the other land use $\times$ seasonal effects, which all had inclusion probabilities less than $2 \%$. Of the MDF metrics, HA$\mathrm{iFLS} \times$ season was primarily driving this relationship, and having a positive influence on the score (Table 4).

Land-use variables at the riparian and reach scale generally had less influence on the score and a lower probability of being included in any model, compared with catchment-scale variables (Table 3 and Appendix B). Riparian-scale urban and reach-scale grass had 


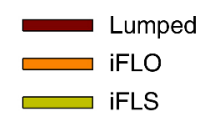

a) EHMP score

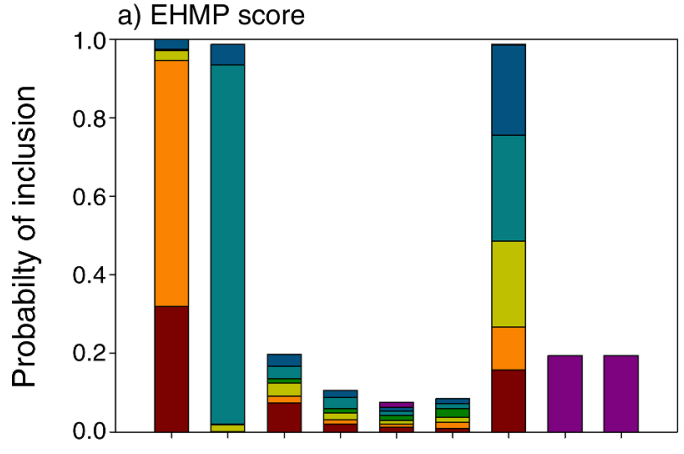

c) Macroinvertebrate indicator

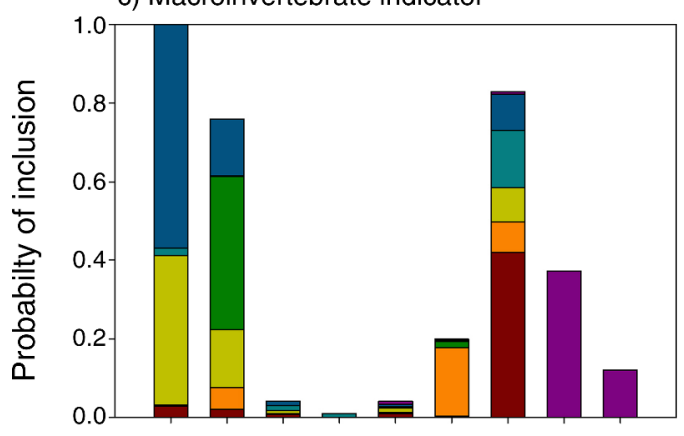

e) Ecosystem processes indicator

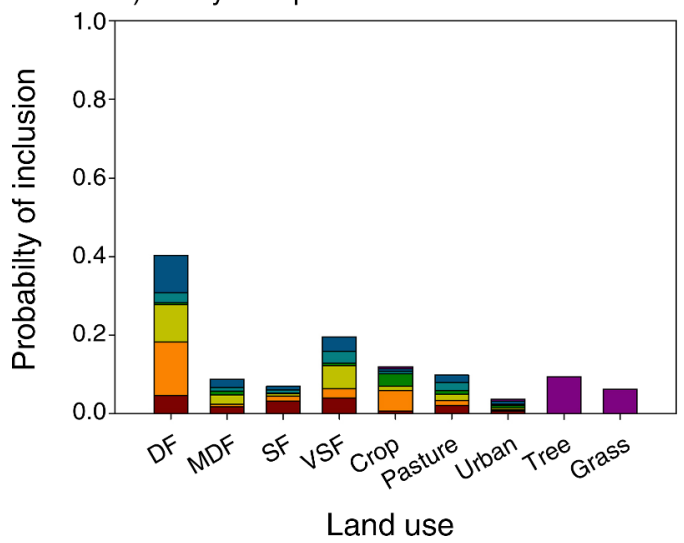

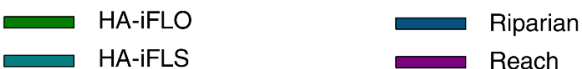

b) Water quality indicator
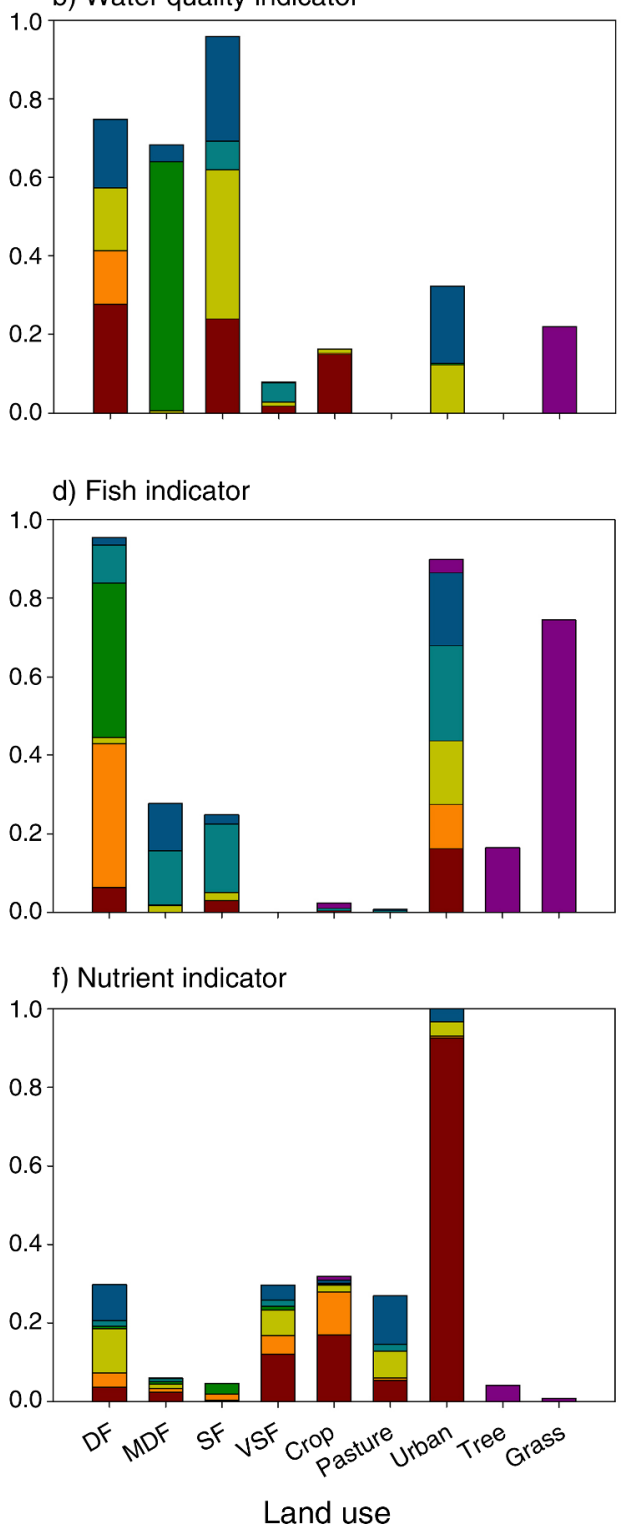

FIG. 5. Total inclusion probability for each land-use type by catchment-, riparian-, and reach-scale metrics. Plots are (a) EHMP score and (b-f) individual ecosystem health indicators: (b) water quality indicator, (c) macroinvertebrate indicator, (d) fish indicator, (e) ecosystem processes indicator, and (f) nutrient indicator. Land-use codes are explained in Table 1.

relatively high probabilities of being in any one model compared to the other reach and riparian metrics $(23 \%$ and $19 \%$, respectively) and both had a negative relationship with the score (Table 4). Tree at the reach scale also had an inclusion probability of $19.5 \%$ and a positive relationship with the EHMP Score (Table 4), while none of the other riparian or reach-scale variables had inclusion probabilities greater than $5.2 \%$ (Table 3).

\section{Land-use influences on individual indicators}

Summary statistics for the seasonal indicator scores showed similar patterns to the annual score, with scores tending to be higher in the post-wet season (Table 2 and Appendix B). Seasonal fish indicator scores were generally lower than the other indicators, while ecosystem processes indicator scores were high in both seasons (Table 2). Water quality indicator scores tended to be 
TABLE 4. Model-averaged coefficients for each land-use variable and seasonal interaction included in the overall EHMP score model.

\begin{tabular}{|c|c|c|c|c|c|c|c|c|c|}
\hline Scale & $\mathrm{DF}$ & MDF & $\mathrm{SF}$ & VSF & Pasture & Crop & Urban & Tree & Grass \\
\hline \multicolumn{10}{|l|}{ Catchment scale } \\
\hline Lumped & 0.0078 & & -0.0027 & -0.0008 & 0 & -0.0001 & -0.0015 & & \\
\hline iFLO & 0.0232 & 0 & -0.0002 & -0.0003 & 0 & 0 & -0.001 & & \\
\hline iFLS & 0.0007 & 0.0001 & -0.0008 & -0.0011 & 0 & 0 & -0.0022 & & \\
\hline HA-iFLO & 0 & 0 & 0 & 0 & 0 & 0 & 0 & & \\
\hline HA-iFLS & 0.0001 & 0.0047 & -0.0004 & -0.0022 & 0 & 0 & -0.0027 & & \\
\hline Lumped $\times$ season & 0.0018 & 0 & 0 & -0.0037 & 0 & 0 & 0 & & \\
\hline iFLO × season & 0.0009 & 0 & 0 & -0.0002 & 0 & 0 & 0 & & \\
\hline iFLS $\times$ season & 0 & 0.0001 & 0 & -0.0018 & 0 & 0 & 0 & & \\
\hline HA-iFLO $\times$ season & 0 & 0 & 0 & 0 & 0 & & 0 & & \\
\hline HA-iFLS $\times$ season & 0 & 0.0053 & 0 & 0 & 0 & 0 & 0 & & \\
\hline \multicolumn{10}{|l|}{ Riparian scale } \\
\hline Lumped & 0.0006 & 0.0004 & -0.0006 & -0.0013 & 0 & 0 & -0.0022 & & \\
\hline Lumped $\times$ season & 0 & 0.0002 & 0 & -0.001 & 0 & 0 & 0 & & \\
\hline \multicolumn{10}{|l|}{ Reach scale } \\
\hline Lumped & & & & & & -0.0002 & -0.0002 & 0.0045 & -0.0016 \\
\hline Lumped $\times$ season & & & & & & 0 & 0 & 0 & 0 \\
\hline
\end{tabular}

Note: The coefficients for the intercept, rainfall, and season were $0.6646,0.0625$, and -0.0413 , respectively.

higher in the post-wet compared with the pre-wet season across all years, while the mean seasonal scores for the other indicators did not show a consistent seasonal effect; however the lowest scores recorded for all indicators occurred in the pre-wet season (Table 2).

Season and rainfall deviation had a $100 \%$ inclusion probability across all models, for all five ecosystem health indicators. DF also had a high probability of being in any one model, with the exception of the nutrient indicator (Fig. 5). For the water quality indicator the MDF HA-iFLO metric had the highest probability of being in any one model (63\%; Fig. 5b) with the largest seasonal land-use interaction being season $\times$ SF iFLS (Appendix B).

For the macroinvertebrate indicator, forested metrics had the highest inclusion probabilities, and these included riparian DF (57\%), MDF HA-iFLO (39\%), DF iFLS (38\%), and tree (37\%), all having a positive relationship (Fig. 5c and Appendix B). Lumped urban had an inclusion probability of $42 \%$, but had a negative influence on the macroinvertebrate indicator score (Fig. 5 and Appendix B), while all other land-use metrics had inclusion probabilities less than $18 \%$.

In contrast, one reach-scale land-use measure was most important for the fish indicator; reach-scale grass had a 74\% inclusion probability and a negative relationship (Fig. 5d and Appendix B). Three catchment measures had inclusion probabilities greater than $24 \%$; DF HA-iFLO and iFLO had a positive relationship with the fish indicator score, while urban close to the stream (riparian and HA-iFLS) had a negative influence (Fig. 5d and Appendix B). In addition, there was no evidence of seasonal interactions with any of the measured landuse metrics for the fish indicator (Appendix B).

Land use at the catchment, riparian, or reach scale had little effect on the ecosystem processes indicator (Fig. 5e and Appendix B). At the catchment scale, the
DF iFLO metric had the highest inclusion probability (13\%) and a positive relationship, however, none of the riparian or reach-scale land-use variables had more than a 10\% inclusion probability (Appendix B). There was also no evidence of a significant seasonal interaction with any of the land-use variables for the ecosystem processes indicator (Appendix B). For the nutrient indicator, lumped urban had a negative influence on the indicator and had the highest probability of being in any one model (93\%), which was much larger than all of the other potential land-use metrics (Fig. 5f and Appendix B). Although the inclusion probability for catchment-scale lumped urban $\times$ season was relatively small (7.24\%), it had a positive coefficient, suggesting that urban areas have a slightly stronger influence on the nutrient indicator scores in the post-wet season compared to the pre-wet season (Appendix B).

\section{Modeling the influence of restoration}

EHMP sites in the Mooloolah catchment (good to excellent health) currently have an average of about $65 \%$ MDF cover and the seasonal score model results suggest that MDF HA-iFLS must be increased to $80 \%$ to consistently achieve a report card grade of $\mathrm{B}+$ to $\mathrm{A}$ (excellent health) (Fig. 6a). For the Caboolture Catchment, which consistently receives moderate ecosystemhealth grades, model results also suggest that MDF HAiFLS needs to be increased from the current average of approximately $50 \%$ to $80 \%$ to achieve a report card grade of $\mathrm{B}+$ to $\mathrm{A}$ (excellent health) (Fig. 6b). A more extreme land-use change would be necessary in the Redlands catchment (poor health), where model results suggest that an MDF HA-FLS value of $100 \%$ must be achieved to obtain an EHMP report card grade of $\mathrm{B}$. However, increasing the cover of MDF HA-iFLS to $60 \%$ could have a positive outcome by consistently returning a report card grade of $\mathrm{C}$ (Fig. 6c). 

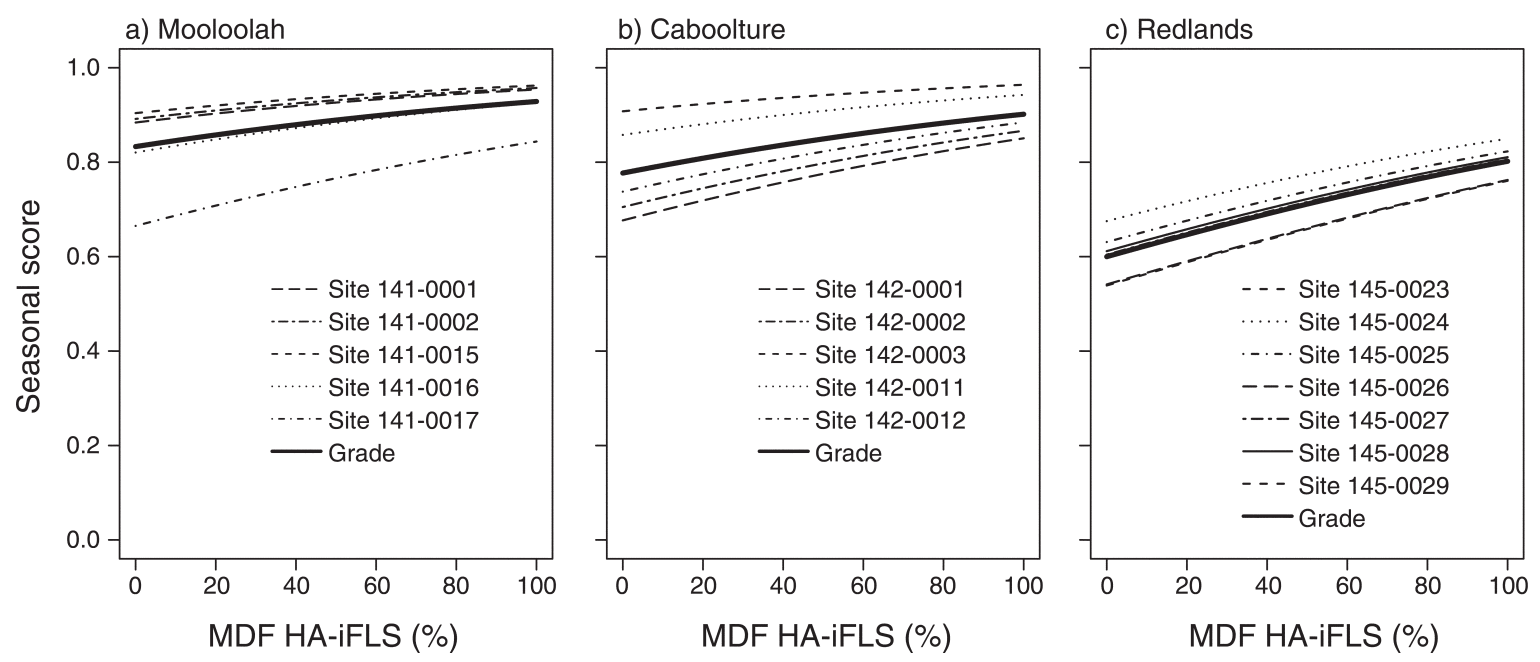

FIG. 6. Predicted change in seasonal score for (a) the Mooloolah River, (b) the Caboolture, and (c) the Redlands report card regions, with increasing hydrologically active inverse distance-weighted mid-dense forest (MDF HA-iFLS) in the catchment. Changes are provided for each site within the catchment (various dotted lines) and the overall average EHMP report card grade (solid line).

\section{DiscusSION}

\section{Land use and stream ecosystem health}

The 14 EHMP indices were originally chosen to document the ecosystem health of SEQ rivers and streams because they responded to a disturbance gradient of land-use change, channel condition and water quality (Bunn et al. 2010). This relationship was also evident in the association between the aggregated EHMP score and catchment land use. In general, catchments obtaining a report card grade of $\mathrm{F}$ had lower lumped percentages of dense forest and higher percentages of urbanization at the catchment and riparian scales, while the opposite was true in catchments consistently obtaining report card grades of B or higher. However, our goal was not to identify a relationship between land use and ecosystem health, which in itself is well-established (Allan 2004, Wasson et al. 2010). Instead, it was to identify the spatial scale of land use, or the combination of spatial scales, that most strongly influences the overall ecosystem health score. In addition, we wanted to determine whether the most influential scale differed for different aspects of ecosystem health (Fig. 2). Given that restoring ecosystem health is the focus of many stream restoration projects (Bernhardt and Palmer 2007, Lake et al. 2007), our approach can be used to identify the scale and catchment position of restoration that would likely result in the greatest improvement of ecosystem health in regional streams and rivers.

\section{Land use, climate, and the EHMP score model}

Spatially explicit representations of land use at the catchment scale have previously been shown to explain more variation in median ecosystem health indices compared with lumped catchment metrics (Peterson et al. 2011) and the same held true for the aggregated EHMP score (Fig. 5). This suggests that all forested areas throughout the catchment have the potential to positively influence the EHMP score, but that MDF in areas of close proximity to the stream or survey site, and in areas with a high probability of contributing overland flow, have the strongest positive influence.

The fact that three urban land-use measures had nearly equal inclusion probabilities likely results from the relatively coarse spatial resolution of the land-use data and the way that HA-iFLS and iFLS metrics allocate the largest weighting to those areas directly adjacent to the stream. The urban HA-iFLS metric had a slightly higher inclusion probability than the other two metrics suggesting that urbanized near-stream areas with the potential for overland flow may more negatively impact the EHMP score. However, lateral connectivity in an urban area is expected to be strongly influenced by non-natural mechanisms including storm-water drainage pipes and connection via impervious surfaces such as roadways and paths (Walsh and Kunapo 2009). As such, stream proximity in urbanized catchments is altered and we would expect urban areas that are directly connected to the stream via storm water piping to have an equally strong negative influence on ecosystem health.

We focused on understanding how the spatial scale of land-use influences ecosystem health and found that this scale could change depending on temporal factors such as season and antecedent rainfall. In our models, explanatory variables representing season and antecedent rainfall had an inclusion probability of 1 , which is not surprising given that flow and connectivity between sites are expected to favor all the component indicators within the EHMP score (Poff et al. 1997). Admittedly, our data set covers an extreme period of drought in SEQ 
and consequently there are no significant periods of sustained above-average flow, which could also have a negative influence on ecosystem health through the component indicators (Pires et al. 2008).

Mean pre-wet scores were consistently lower than post-wet scores (Table 2), highlighting the importance of seasonal variability on ecosystem health. In SEQ the pre-wet season occurs in spring, which is often a time of low rainfall and streamflow, with high air and water temperatures. The model coefficient for season was negative, indicating that post-wet season scores were lower than the pre-wet season. At first, these results seemed counterintuitive, but the negative influence of the seasonal effect appears to be negated by the strong positive influence of the seasonal MDF interaction on the EHMP score. When MDF values were low $(<7.79 \%)$, MDF had a negative relationship with the score and this effect was stronger in the post-wet season (Appendix B). This suggests that catchments with little forest cover were more likely to have low EHMP scores in the post-wet season due to runoff from sparsely vegetated areas. However, there was also a strong seasonal interaction with MDF HA-iFLS; as the amount of MDF increased past $7.79 \%$, the expected positive post-wet seasonal effect was captured through the seasonal interaction term with MDF (Appendix B). This indicates that the positive influence of MDF was strongest in the post-wet season when there was a higher likelihood of catchment runoff.

\section{Land-use influence on component indicators}

By exploring the influence of land-use scale on the aggregated EHMP score, we may miss some of the complexities of differential effects within the component indicators. Peterson et al. (2011) found that different landscape-representation metrics explained the most variation in EHMP fish, macroinvertebrate, and water quality indices (Fig. 2). This is not surprising since the 14 ecosystem health indices were initially selected because they responded to a disturbance gradient that included land-use change and channel condition (Bunn et al. 2010). Our analyses also suggest that the five aggregated indicators of ecosystem health displayed differential relationships with land use across various spatial scales, with no single land-use scale consistently explaining variation in all indicators.

Forested areas at multiple spatial scales tended to have a strong influence on the water quality indicator suggesting that forested areas anywhere in the catchment can have a positive influence on water quality, but that those areas that are in close proximity to the stream or survey site have the strongest influence. This reach and riparian-scale effect of land use is likely influencing the 24-h measures of dissolved oxygen (DO) and temperature range, which are known to respond strongly to local riparian cover (Rutherford et al. 2004, Fellows et al. 2006), whereas the measures of conductivity and $\mathrm{pH}$ are likely reflecting catchment-wide land use (Peterson et al. 2011).

The macroinvertebrate indicator was also strongly related to land use at multiple scales. Forested areas near the stream or site tended to have a strong positive influence, while urban areas had an equally negative influence on the indicator, regardless of proximity to the stream or survey site. The positive influence of forests reflect the overriding influence of riparian vegetation on stream macroinvertebrates (Baxter et al. 2005), where a large proportion of insect larvae and nymphs mature into terrestrial adults, which require riparian vegetation for survival (Smith et al. 2009). This is especially true of the insect orders Ephemeroptera (mayflies), Plecoptera (stoneflies), and Trichoptera (caddisflies) that make up the EPT richness index (Sponseller et al. 2001). The negative influence of urban areas did not appear to be related to the spatial proximity of land use in the catchment and this may reflect the complexities of the urban land-use signal. Urban areas anywhere within a catchment can be connected to the stream network through storm water pipes and other artificial drainage mechanisms (Walsh and Kunapo 2009), which may influence macroinvertebrates through changes in water quality, reduced habitat availability or directly through increased flow velocity (Walsh et al. 2007).

The fish indicator also tended to be more strongly related to land use near the stream or survey site. These results are not surprising since the fish indices that comprise the fish indicator responded most strongly to local-channel condition and in-stream habitat in the original EHMP design study (Kennard et al. 2006, Bunn et al. 2010). This also makes sense from a mechanistic standpoint; there is likely to be poor in-stream channel habitat where the surrounding land is dominated by grass or in highly urbanized areas, which is likely due to a lack of in-stream wood, known to have a positive influence on the EHMP fish indices (Kennard et al. 2006).

Indices within the ecosystem process indicator have been shown to respond to local site measures of canopy cover and nutrients (Fellows et al. 2006), and this site effect may not have been captured in this study, given that our finest land-use scale was the 1-km upstream reach. To capture these site-scale influences on ecosystem processes, a land-use metric based on the inverse flow length to the outlet and generated using fine-scale land-use data would need to be tested. Although the relationship was not strong, the nutrient indicator was most influenced by the percentage of urbanization in the catchment, suggesting that urbanization anywhere within the catchment has a negative impact on nutrient processing. In addition, our results show that this negative influence may be slightly stronger in the postwet season, perhaps reflecting the impact of increased runoff from impervious surfaces in urban areas (Walsh and Kunapo 2009). 


\section{Restoration scenarios}

One common option for restoring the integrity of streams and rivers is the reinstatement of riparian vegetation, particularly in systems where land-use change is the primary driver for reductions in stream ecosystem health (Lake et al. 2007, Palmer et al. 2009). Much of this restoration, however, is undertaken without an understanding of the scale required for measurable positive outcomes; as such, there is a risk that the scale of the restoration will be insufficient to detect an ecosystem response. The methods used to generate the restoration scenarios presented here may be used to identify the quantity and spatial location of restoration activities; thus, providing critical information needed to guide investments in stream and catchment restoration. We focused on the MDF HAiFLS metric because it had the strongest relationship to ecosystem health in the EHMP score models. The scenario results suggested that only a minor increase in the EHMP score could be gained for a relatively large restoration effort in catchments that were already in good to fair ecosystem health. In the Redlands catchment, however, the scenarios suggested that catchment ecosystem health could increase from a fail ( $\mathrm{F}$ grade) to moderate ( $\mathrm{C}$ grade) by restoring a relatively large portion of hydrologically active near-stream areas, which given the highly urbanized nature of the catchment, may be acceptable.

These restoration models, while as yet untested in the field, provide some guidance to the level of restoration required for positive ecosystem health outcomes and could therefore provide the predictive framework for testing the scale of appropriate restoration for the rivers and streams in SEQ. However, we recognize that the scale we have identified may not be true for every catchment or site and may not be transferable between catchments, and any restoration activities guided by this analysis would need to be appropriately monitored as a test of the effectiveness of this scale of intervention (Palmer et al. 2009). The EHMP score is an aggregate of five indicators and only three of those (water quality, macroinvertebrates, and fish) demonstrated a strong statistical relationship with forested land use. In addition, the most influential spatial scale of forested area tended to be areas close to the stream or the site, depending on the indicator. When an indicator is strongly influenced by near-site land use (e.g., iFLO, HA-iFLO, or the reach), the implication is that restoration of the local riparian area will only have a positive influence a short way downstream. However, if a site is strongly influenced by near-stream land use (iFLS, HA-iFLS, or riparian), then the influence of restoration will have a strong influence further downstream. From a restoration perspective, more of the riparian zone would need to be restored to improve catchment-wide ecosystem health when near-site land use is important. Restoration efforts geared toward improving these three EHMP ecosystem health indica- tors should therefore be targeted in the HA-iFLS zone because the goal is to improve the ecosystem health throughout SEQ streams, rather than at individual sites. Our study does not provide evidence that increasing the amount of forest cover in this zone will have the same effect on the ecosystem processes and nutrient indicators. However, previous research undertaken in SEQ suggests that improving water quality and increasing riparian canopy cover would also positively influence the individual ecosystem processes and nutrient indices (Fellows et al. 2006, Udy et al. 2006).

\section{Conclusions}

As with similar monitoring programs worldwide (Williams et al. 2009) the management response to declining ecosystem health usually lies in stream and catchment restoration (Bernhardt and Palmer 2007, Lake et al. 2007), but the missing piece in the restoration puzzle is how much restoration is needed and where it should be targeted to obtain positive ecosystem health outcomes. There is generally a lack of data targeting stream restoration projects (Bash and Ryan 2002, Bernhardt et al. 2005). However, we have assessed restoration potential using an adaptive-management approach, with the results used to identify which spatial scale of land use most strongly influences ecosystem health. Our models suggest that at least $80 \%$ mid-dense forest cover is required in hydrologically active nearstream areas to obtain excellent ecosystem health, but restoration at other spatial scales may also be required (Li et al. 2001). Increasing forest cover in the hydrologically active region of the stream would influence water quality by mediating the $24-\mathrm{h}$ temperature and dissolved oxygen range. It would also provide habitat for macroinvertebrates, promote bank stability and habitat for fish, and would positively influence site-scale ecosystem processes.

Most studies that explore the relationship between land use and stream ecosystem health focus on the response of a single index or a group of related indices. We demonstrate a significant influence of land use on ecosystem health, even after the indices were standardized against reference conditions and averaged to produce an overall EHMP score (Fig. 2). Our results suggest that when a monitoring program is appropriately designed to detect disturbance associated with broad-scale land-management practices (Bunn et al. 2010), then these influences may also be detected in a single aggregated score. This indicates that an ecosystem health report card grade, such as that used by the EHMP, is a powerful management tool. It maintains the integrity of an ecologically diverse set of monitoring results, while also being easy to understand and communicated to non-scientific audiences, who may be responsible for decisions about restoration funding. The monitoring and assessment framework demonstrated here provides critical information for guiding investments in stream and catchment restoration at a scale 
that will have positive outcomes for river ecosystems and their catchments.

\section{ACKNOWLEDGMENTS}

This project was funded under an Australian Research Council Linkage Grant (LP0668369), with additional funding provided by the CSIRO Water for a Healthy Country Flagship and the Healthy Waterways Partnership. We thank the Healthy Waterways Partnership, who provided access to the EHMP data from 2002 until 2008, as well as Nick Ellis and two anonymous reviewers who provided valuable feedback on previous versions of the manuscript.

\section{Literature Cited}

Abal, E. G., S. E. Bunn, and W. C. Dennison, editors. 2005. Healthy waterways, healthy catchments: making the connection in South East Queensland. Moreton Bay and Catchments Partnership, Brisbane, Queensland, Australia.

Allan, J. D. 2004. Landscapes and riverscapes: the influence of land use on stream ecosystems. Annual Review of Ecology and Systematics 35:257-284.

Bash, J. S., and C. M. Ryan. 2002. Stream restoration and enhancement projects: is anyone monitoring? Environmental Management 29:877-885.

Baxter, C. V., K. D. Fausch, and C. W. Saunders. 2005. Tangled webs: reciprocal flows of invertebrate prey link streams and riparian zones. Freshwater Biology 50:201-220.

Bernhardt, E. S., and M. A. Palmer. 2007. Restoring streams in an urbanizing world. Freshwater Biology 52:738-751.

Bernhardt, E. S., et al. 2005. Synthesizing U.S. river restoration efforts. Science 308:636-637.

BRS. 2002. Land use mapping at catchment scale: principles, procedures and definitions, second edition. Bureau of Rural Sciences, Department of Agriculture, Fisheries, and Forestry, Kingston, ACT, Australia.

Bunn, S. E., E. G. Abal, M. J. Smith, S. C. Choy, C. S. Fellows, B. D. Harch, M. J. Kennard, and F. Sheldon. 2010 Integration of science and monitoring of river ecosystem health to guide investments in catchment protection and rehabilitation. Freshwater Biology 25:223-240.

Bunn, S. E., P. M. Davies, and T. D. Mosisch. 1999. Ecosystem measures of river health and their response to riparian and catchment degradation. Freshwater Biology 41:333-345.

DERM. 2008. Digital orthophoto data for South-East Queensland, Licence Nos. SSL_2008_0844, SSL_2008_0938, SSL_2009_1109. Department of Environment and Resource Management, Queensland, Australia.

Fellows, C. S., J. Clapcott, J. Udy, S. E. Bunn, B. D. Harch, M. J. Smith, and P. M. Davies. 2006. Benthic metabolism as an indicator of stream ecosystem health. Hydrobiologia 572:71-87.

Frissell, C. A., W. J. Liss, C. E. Warren, and M. D. Hurley. 1986. A hierarchical framework for stream habitat classification: viewing streams in a watershed context. Environmental Management 10:199-214.

Harris, J. H., and R. Silveira. 1999. Large-scale assessments of river health using an Index of Biotic Integrity with lowdiversity fish communities. Freshwater Biology 41:235-252.

Healthy Waterways Partnership. 2012. Ecosystem Health Monitoring Program. Healthy Waterways Partnership, Brisbane, Australia. http://www.healthywaterways.org/ehmphome.aspx

Hoeting, J. A., D. Madigan, A. E. Raftery, and C. T. Volinsk. 1999. Bayesian model averaging: a tutorial. Statistical Science 14:382-417.

Hynes, H. B. N. 1975. The stream and its valley. Verhandlungen der Internationalen Vereinigung für theoretische und angewandte Limnologie 19:1-15.

Jeffrey, S. J., J. O. Carter, K. B. Moodie, and A. R. Beswick. 2001. Using spatial interpolation to construct a comprehen- sive archive of Australian climate data. Environmental Modelling and Software 16:309-330.

Johnson, L. B., C. Richards, G. E. Host, and J. W. Arthur. 1997. Landscape influences on water chemistry in Midwestern stream ecosystems. Freshwater Biology 37:193-208.

Karr, J. R. 1999. Defining and measuring river health. Freshwater Biology 41:221-234.

Kennard, M. J., A. H. Arthington, B. J. Pusey, and B. D. Harch. 2005. Are alien fish a reliable indicator of river health? Freshwater Biology 50:174-193.

Kennard, M. J., B. L. Pusey, A. H. Arthington, B. D. Harch, and S. J. Mackay. 2006. Development and application of a predictive model of freshwater fish assemblage composition to evaluate river health in eastern Australia. Hydrobiologia 572:33-57.

Kuhnell, C. A., B. M. Goulevitch, T. J. Danaher, and D. P. Harris. 1998. Mapping woody vegetation cover over the state of Queensland using landsat TM imagery. Pages 3201-3223 in T. McVicar, editor. Proceedings of the Land AVHRR Workshop. 9th Australasian Remote Sensing and Photogrammetry Conference. 24 July, 1998, Sydney, Australia. ERDAS, Canberra, Australia.

Kutner, M. H., C. J. Nachtsheim, J. Neter, and W. Li. 2004. Applied linear statistical models. Fifth edition. McGrawHill/Irwin, Columbus, Ohio, USA.

Ladson, A. R., L. J. White, J. A. Doolan, B. L. Finlayson, B. T. Hart, P. S. Lake, and J. W. Tilleard. 1999. Development and testing of an index of stream condition for waterway management in Australia. Freshwater Biology 41:453-469.

Lake, P. S., N. Bond, and P. Reich. 2007. Linking ecological theory with stream restoration. Freshwater Biology 52:597615.

Li, J., A. Herlihy, W. Gerth, P. Kaufmann, S. Gregory, S. Urquhart, and D. P. Larsen. 2001. Variability in stream macroinvertebrates at multiple spatial scales. Freshwater Biology 46:87-97.

Malard, F., K. Tockner, and J. V. Ward. 1999. Shifting dominance of subcatchment water sources and flow paths in a glacial floodplain, Val Roseg, Switzerland. Arctic, Antarctic, and Alpine Research 31:135-150.

Mills, J. A., and K. Prasad. 1992. A comparison of model selection criteria. Econometric Reviews 11:201-234.

Moreton Bay Waterways and Catchments Partnership. 2005. South East Queensland streams and catchments version 2. Moreton Bay Waterways and Catchments Partnership, Brisbane, Australia.

Mosisch, T. D., S. E. Bunn, and P. M. Davies. 2001. The relative importance of shading and nutrients on algal production in subtropical streams. Freshwater Biology 46:1269-1278

Palmer, M. A., H. Menninger, and E. S. Bernhardt. 2009. River restoration, habitat heterogeneity, and biodiversity: a failure of theory or practice? Freshwater Biology 55(Supplement 1):205-222.

Peterson, E. E., A. A. Merton, D. M. Theobald, and N. S. Urquhart. 2006. Patterns of spatial autocorrelation in stream water chemistry. Environmental Monitoring and Assessment 121:569-594.

Peterson, E. E., F. Sheldon, R. Darnell, S. E. Bunn, and B. D. Harch. 2011. A comparison of spatially explicit landscape representation methods and their relationship to stream condition. Freshwater Biology 56:590-610.

Piepho, H. P. 2003. The folded exponential transformation for proportions. Statistician 52:575-589.

Pinheiro, J. C., and D. M. Bates. 2000. Mixed-effects models in $\mathrm{S}$ and S-PLUS. Springer-Verlag, New York, New York, USA.

Pires, A. M., M. F. Magalhaes, L. Moreira Da Costa, M. J. Alves, and M. M. Coelho. 2008. Effects of an extreme flash flood on the native fish assemblages across a Mediterranean catchment. Fisheries Management and Ecology 15:49-58. 
Poff, N. L., J. D. Allan, M. B. Bain, J. R. Karr, K. L. Prestegaard, B. D. Richter, R. E. Sparks, and J. C. Stromberg. 1997. The natural flow regime: a paradigm for river conservation and restoration. BioScience 47:769-784.

R Development Core Team. 2006. R: A language and environment for statistical computing. $\mathrm{R}$ Foundation for Statistical Computing, Vienna, Austria. www.r-project.org

Robertson, A. I., S. E. Bunn, P. I. Boon, and K. F. Walker. 1999. Sources, sinks and transformations of organic carbon in Australian floodplain rivers. Marine and Freshwater Research 50:813-829.

Rutherford, J. C., N. A. Marsh, P. M. Davies, and S. E. Bunn. 2004. Effects of patchy shade on stream water temperature: How quickly do small streams heat and cool? Marine and Freshwater Research 55:737-748.

Sandin, L., and K. R. Johnson. 2004. Local, landscape and regional factors structuring benthic macroinvertebrate assemblages in Swedish streams. Landscape Ecology 19:501515.

Smith, M. J., et al. 1999. AusRivAS: using macroinvertebrates to assess ecological condition of rivers in Western Australia. Freshwater Biology 41:269-282.

Smith, R. F., L. C. Alexander, and W. O. Lamp. 2009. Dispersal by terrestrial stages of stream insects in urban watersheds: a synthesis of current knowledge. Journal of the North American Benthological Society 28:1022-1037.

Sonoda, K., J. A. Yeakley, and C. E. Walker. 2001. Nearstream landuse effects on streamwater nutrient distribution in an urbanizing watershed. Journal of the American Water Resources Association 37:1517-1532.

Specht, R. L., E. R. Roe, and V. H. Boughton. 1974. Conservation of major plant communities in Australia and Papua New Guinea. Australian Journal of Botany Supplement 7:1-667.

Sponseller, R. A., E. F. Benfield, and H. M. Valett. 2001. Relationships between land use, spatial scale and stream macroinvertebrate communities. Freshwater Biology 46:1409-1424.

Stauffer, J. C., R. M. Goldstein, and R. M. Newman. 2000. Relationship of wooded riparian zones and runoff potential to fish community composition in agricultural streams. Canadian Journal of Fisheries and Aquatic Sciences 57:307-316.

Stephenson, J. M., and A. Morin. 2009. Covariation of stream community structure and biomass of algae, invertebrates and fish with forest cover at multiple spatial scales. Freshwater Biology 54:2139-2154.
Tong, S. T. Y., and W. Chen. 2002. Modeling the relationship between land use and surface water quality. Journal of Environmental Management 66:377-393.

Udy, J., C. S. Fellows, M. Bartkow, S. E. Bunn, J Clapcott, and B. Harch. 2006. Measures of nutrient processes as indicators of stream ecosystem health. Hydrobiologia 572:89-102.

Utz, R. M., R. H. Hilderbrand, and D. M. Boward. 2009. Identifying regional differences in threshold responses of aquatic invertebrates to land cover gradients. Ecological Indicators 9:556-567.

Vörösmarty, C. J., P. B. McIntyre, M. O. Gessner, D. Dudgeon, A. Prusevich, P. Green, S. Glidden, S. E. Bunn, C. A. Sullivan, C. R. Liermann, and P. M. Davies. 2010. Global threats to human water security and river biodiversity. Nature 467:555-561.

Walsh, C. J., and J. Kunapo. 2009. The importance of upland flow paths in determining urban effects on stream ecosystems. Journal of the North American Benthological Society 28:977-990.

Walsh, C. J., K. A. Walker, J. Gehling, and R. MacNally. 2007. Riverine invertebrate assemblages are degraded more by catchment urbanisation than by riparian deforestation. Freshwater Biology 52:574-587.

Wasson, J. G., B. Villeneuve, A. Iital, J. Murray-Bligh, M. Dobiasova, S. Bacikova, H. Timm, H. Pella, N. Mengin, and A. Chandesris. 2010. Large-scale relationships between basin and riparian land cover and the ecological status of European rivers. Freshwater Biology 55:1465-1482.

Weijters, M. J., J. H. Janse, R. Alkemade, and J. T. A. Verhoeven. 2009. Quantifying the effect of catchment land use and water nutrient concentrations on freshwater river and stream biodiversity. Aquatic Conservation-Marine and Freshwater Ecosystems 19:104-112.

Williams, M., B. Longstaff, C. Buchanan, R. Llanso, and W. Dennison. 2009. Development and evaluation of a spatiallyexplicit index of Chesapeake Bay health. Marine Pollution Bulletin 59:14-25.

Wright, J. F., M. T. Furse, and P. D. Armitage. 1993. RIVPACS: technique for evaluating the biological quality of rivers in the UK. European Water Pollution Control 3:1525.

Young, R. G., and K. J. Collier. 2009. Contrasting responses to catchment modification among a range of functional and structural indicators of river ecosystem health. Freshwater Biology 54:2155-2170.

\section{Supplemental Material}

Appendix A

Bayesian model-averaging approach and stochastic model search (Ecological Archives A022-118-A1).

Appendix B

Seasonal score model-averaged coefficients, standard errors, and inclusion probabilities (Ecological Archives A022-118-A2). 